NEUROLOGICAL PICTURE

\title{
Post-encephalitic parkinsonism
}
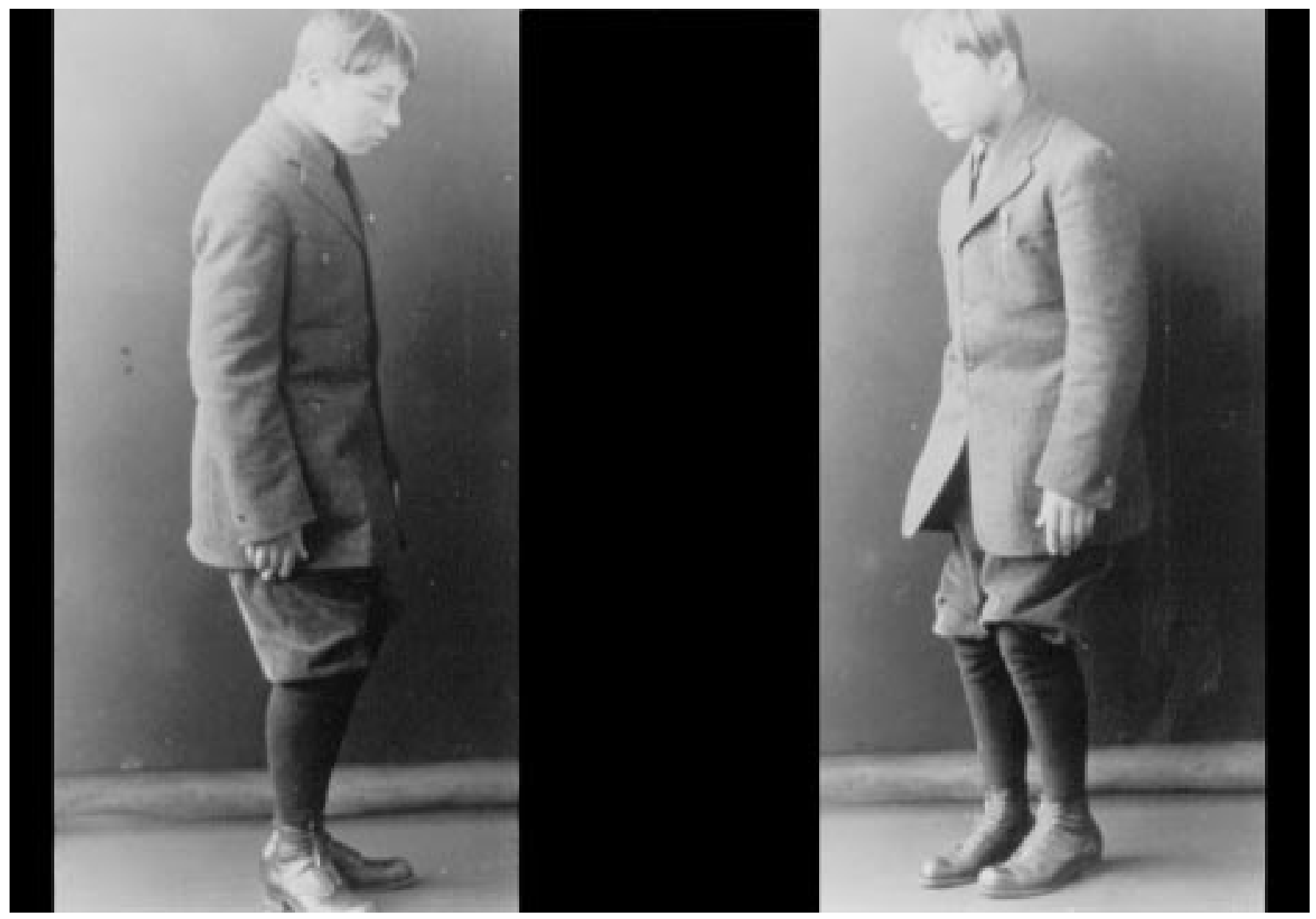

This is a rare unpublished photograph preserved by Professor Emeritus Donald W Mulder, MD, of a young boy who was seen at the Mayo Clinic in Rochester somewhere between 1920 to 1930, who was diagnosed with post-encephalitic parkinsonism. His rigid stance is associated with a stooped posture, paucity of facial expression, slightly flexed knees, and arms stiffly fixed at the sides. On initiating a step, the patient gives the impression of a shuffling gait.

Encephalitis lethargica, also known as von Economo's encephalitis, was a global pandemic that affected more than a million people all over the world from 1915 to 1930. Although parkinsonism was occasionally seen during the acute encephalitic phase of encephalitis lethargica, it was often encountered in the post-encephalitic phase. The onset of postencephalitic parkinsonism can be delayed by several years from the resolution of encephalitis lethargica.

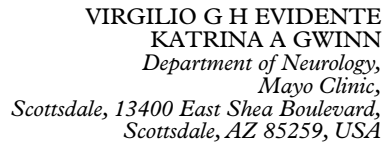

Correspondence to:Dr K A Gwinn. 